\title{
Organicism and an enviro-organic form integrating to the built environment
}

\author{
Duc $\operatorname{Tran}^{1, *}$ \\ ${ }^{1}$ University of Architecture, 196 Pasteur st., Dist.3, Ho Chi Minh City, Vietnam
}

\begin{abstract}
This research intends to the understanding of organicism as the historic source of architectural forms. Organic architecture acts as a junction between humans and nature, where humans are seen as parts of nature. Through organicism as an apparatus, designers are able to respond to nature in such manner that humans are more intimately bound into the entirety of nature to form an organic whole. A new term "enviro-organic" is proposed in this research. Enviro-organic form extends prior definitions of organic architecture, which are of greater relevance today. Such form is defined as one that opens to the natural world, facilitating the making of architecture that sustains human life and nature today and in the future.
\end{abstract}

\section{Introduction}

In the $20^{\text {th }}$ century, in concert with technological and industrial developments, many schools of thought emerge and evolve. Among those, modern architecture dominates and becomes the mainstream because of its preeminent theory of function. The Classical organicism is seen to be no longer relevant within secular humanism, and the rise of scientific method. However, this worldview is not monolithic, and there remain some architects that have continued the project of "Organic Architecture". From the middle of the 20th century, the mechanistic world view is gradually replaced by Einstein's theory of relativity and quantum theory. In this context, different from traditional organicism, organic forms are no longer considered as objects separated from their locations in space and time. Concepts of space-time, fractal geometry, and other concepts have influenced a return to organicism and a new impact on architectural design in 21th century. Concepts and definitions of organic form have anopening to be transformed in the light of this new paradigm [1].

The research shows that the organic forms of nature are enmeshed in the life world of humans. Various applications and interpretations of nature cause many assumptions in organic architectural forms. However, architecture as a unity of form and function is always organic, because it embodies the human impulse to question their relationship to nature in their endless quest to derive the meaning of existence in the world. Accordingly, this paper aims at enviro-organic form that is born from humanity's internal and external needs in form, function and meaning, in which nature is the source of design. The organic is recalled in human memories of nature, not by perfectly reproducing nature's form, but reinterpreting and transforming natural form to constitute an organic understanding of life. Nature shares

\footnotetext{
* Corresponding author: ductran@hawaii.edu
} 
with architectural form its shapes, growth, unity and principles. Through metamorphosis, spirit, and body, living nature and form coexist.

In addition, humans are animals, living organisms that share common characteristics with other natural organisms. A system of form and function is changeable and responsive. At any moment of an altering process, disorganization becomes reorganized. The fluctuation purposes the formulation of an existent form on a higher level that corresponds to changed conditions. Thus, the paper also displays enviro- organic form consists of natural and rational processes that mediate the impacts of nature with human aspirations. Due to human consciousness and agency, enviro- organic form is born from an inorganic form and gradually evolves to a complex built organic form [2].

\section{Literature review}

Organicism is based on the premise that the universe is an orderly whole and alive. In architecture, it refers to complexity, individuality, imagination, and the relation to nature from inside to outside. According to the organic idea, function serves as the interactive functional network, with its form as the temporal dynamic network. Different from modernism architecture, organism denotes "form from function" and sometimes form goes beyond function to get the function of expression. In other words, form relies on function and they act mutually. Therefore, no single work of architecture may be deemed absolute organic, functionalist, formalist, or expressionist. Depending on design orientation, each of those characters may be relevant to the building appearance [3].

Humans have created buildings based on geometry. At times this is done with rational intension, and at other times, using intuition alone. We plan and think on some architectural design harmoniously, somehow like Plato said, the world is just image of perception, so in our memory, as well as in our mind, dynamic spaces, including natural elements, such as tree, water, sky, terrain, architecture, and people are enacted. Such dynamic spaces would naturally become architectural works with different levels if they are successfully grasped.

Geometrical symmetry is common attributefound in natural and human objects. While symmetrical balance is common, asymmetrical form is also present, and gives a counterbalance, displaying the existence of diversity in the world of forms. The basic geometries are derived from the shapes and motions of celestial bodies, which transform geometry into abstract form and nurture human's perception on the so-called beautiful mathematical forms [4]. Mathematics and geometry are human constructs intended to reveal hidden patterns of order in nature. Some types of order have a much higher level of complexity than can be described by Euclidean geometry. Mandelbrot's Fractal geometry accounts for such complexity found in nature, such as topographic form and plant growth patterns.

\section{Materials and method}

Following the organic idea in the remarkable works On Growth and Formand On Growth and form: Organic Architecture and Beyond, this research aimed at uncovering the key attributes of natural form, in order to allow the design of enviro-organic form. The research questions comprised: What architectural form best fits the spirit of the age? And how might we derive form that satisfies human needs of function and aesthetics vis-a-vis learning from and integrating to nature?To address these questions, this research focused on: Tracing the historical development of the concepts and definitions of organism as applied to organic architecture; and defining the concept of enviro-organic form according to transformation of form $[5,6]$. To carry out the mentioned targets the following methods have been used: 
- Historical Research: To investigate the source and chronology of organicism, human and nature motivations on form, structure and architectural composition through historical periods of architecture, synthesize practical knowledge of existing buildings based on experience of natural principles and of the principles of architectural space, and discover key commonality of compositional structure between nature and architectural form,

- Logical Argumentation: To argue the relationship between nature and architecture convincingly, geometrical principles and fractal geometry are used to analyze natural structure and architectural form,

- Descriptive Method: To analyze the geometry inherent in enviro-organic strategies in architectural form, function, andharmony impacted by nature, to systematize knowledge following logical argumentation in each case; and to build up the foundational design methods [7].

\section{Results}

\subsection{Source of architectural imitation}

Nature has been a key inspiration for human beings in the design and construction of building sat all times and places. The influence of nature on humans not only includes its actual and perceived forms, but also its material energy, information channels, and processes. Humans are not only dwellers on the earth, but also transformers of the earth through their incursions into nature in order to adapt it to their purposes. Learning from nature thus is defined as organicism, which involves the imitation of nature, including the operations of mimesis and metaphor. It is considered as a purposive strategy or the conceptual tool of architectural form making. Organicism is not employed and developed as a science, but is framed as a guide for the creative process, and for the interpretation of art and architecture.

When humans interacted with nature, natural phenomena were observed and applied to the way people built their structures. The organic features of the surrounding environment were imprinted on their shelters. Thus, human building was informed with intuitive and theoretical models of living structures, such as organization, adaptation, selection, transformation, simplicity, complexity, and diversity.

Following Darwin's theory of evolution, organic architecture originated from human selection in interplay with nature. In certain stages, each of the organic types is born, with different names, evolving successful attributes and fixing the weaknesses of previous forms, in order to adapt to and fit human demands in relation to natural conditions. According to Thompson, this fit would result from "equilibrium is explained by the interaction or balance of forces" (D'Arcy Wentworth Thompson, "Introductory," in On Growth and Form (Cambridge: University Press, 2014), The motivations in making form are simplified and converted to physical forces, and able to be visualized. Different intensities of those agencies in each case result in a specific form. The form becomes a diagram and record of dynamic processes in nature's growth. Therefore, by understanding the natural process leading to form, we can direct a conscious human process of design and construction leading to practical and artistic objects.

The similarity consolidates its position when, in his famous work, On Growth and Form, Thompson also argues that natural forms, such as plants and animals, could be understood in part by using mathematics, typically geometry, through description and analysis. He discloses the world as a symphony of forces and geometries, witnessed in dynamic growth and physical processes. The laws that govern an organism's dimensions and development are codified in the growth of cells and tissues. The processes comprise the phenomena of packing, membranes under tension, symmetries, and division of single cells, as well as 
engineering and geodesics of simple organism skeletons. Thompson's work had astrong influence on modern architecture between the world wars. It opened a line of reasoning that Abbé Laugier expounded in his discourse on the "Primitive hut". He argued in the 18th century that organicism is a basic instinct of man. Thompson's theories also link to architectural theory in the 19th century. Ideas by Ruskin, Viollet-le-Duc, and others, sought to unite scientific, aesthetic, and spiritual knowledge via developments in science, biology, and mathematics. On Growth and form: Organic Architecture and Beyond, these lines of thought link architectural principles with evolutionary processes of nature, and established two formal typologies in modern architecture: rational-empirical and pure organic form.

The historical development of organicism can be defined three stages: prehistoric (or animism), classic (mythology), and modern. In the first period, humans depended on nature and an architecturally organic manifestation that may be referred to as primitive organicism. This is seen in the form of simple structures, such as primitive huts, tents, cave dwellings, and monumental works such as Dolmen and Stonehenge. In the mythological period, humans admired and discovered the natural world. This way of thinking produced imitative natural shapes including structures and ornaments. They are developed according to three types of organicism in the successive order: tectonic, religious, and scientific. In the last period, beginning in the early 20th century, humans developed knowledge in the natural sciences and construction technology. Organic manifestations in architecture were produced by interpreting nature's laws and tempering these with social and cultural factors. In the early modern period, organicism (officially termed Organic Architecture) is divided into the types of mechanical and traditional organicism. From 1960s, the mechanical type becomes divided in two types: regional and high-tech organicism. In turn, these two types converge to hightech organicism, also referred to as bio-mimetic architecture. This line of development sought to achieve a higher level of comfort, protection, and energy efficiency. In contrast, traditional organicism continued with the only purpose of integrating buildings formalistically into the natural environment.

\subsection{Form transformation}

Organicism flows continuously in architectural history. In each of era, specific organic forms appear from simple to complex, with the universal idea of compatibility between the whole and its parts, based on the equilibrium of psychology and aesthetics. The concept of organicism as the growth of nature begins from the Organic Architecture stage. However, pure organic form depends on the individual styles, those who understand the power of site. They are considered as the geometrical and harmonious whole in which its parts are interwoven to express the growth spirit of nature. Geometrical elements are deformed together with architects' endeavors of integration to site. They are art works of human reflection on nature filtered through a cultural lens.

Other modern architectural movements reflect the growth spirit of nature through applying nature's principles, such as proportion, physical forces, symmetry, and composition. Yet often there is a focus on function and its growth, physical structures and economics, whereby the integration between form and its site becomes abstract, or even separated.

In the evolution of the concepts of organicism and organic architecture, organic forms have still not achieved the status of a fully-constituted object. It belongs to human's perception of nature and the role of the building in place in which the building is the witness or memory of space and time, and where the place attends to the form-making. The development of the concept of organicism continues to evolve in a reciprocal relation to the birth of its forms [Figure 1]. 


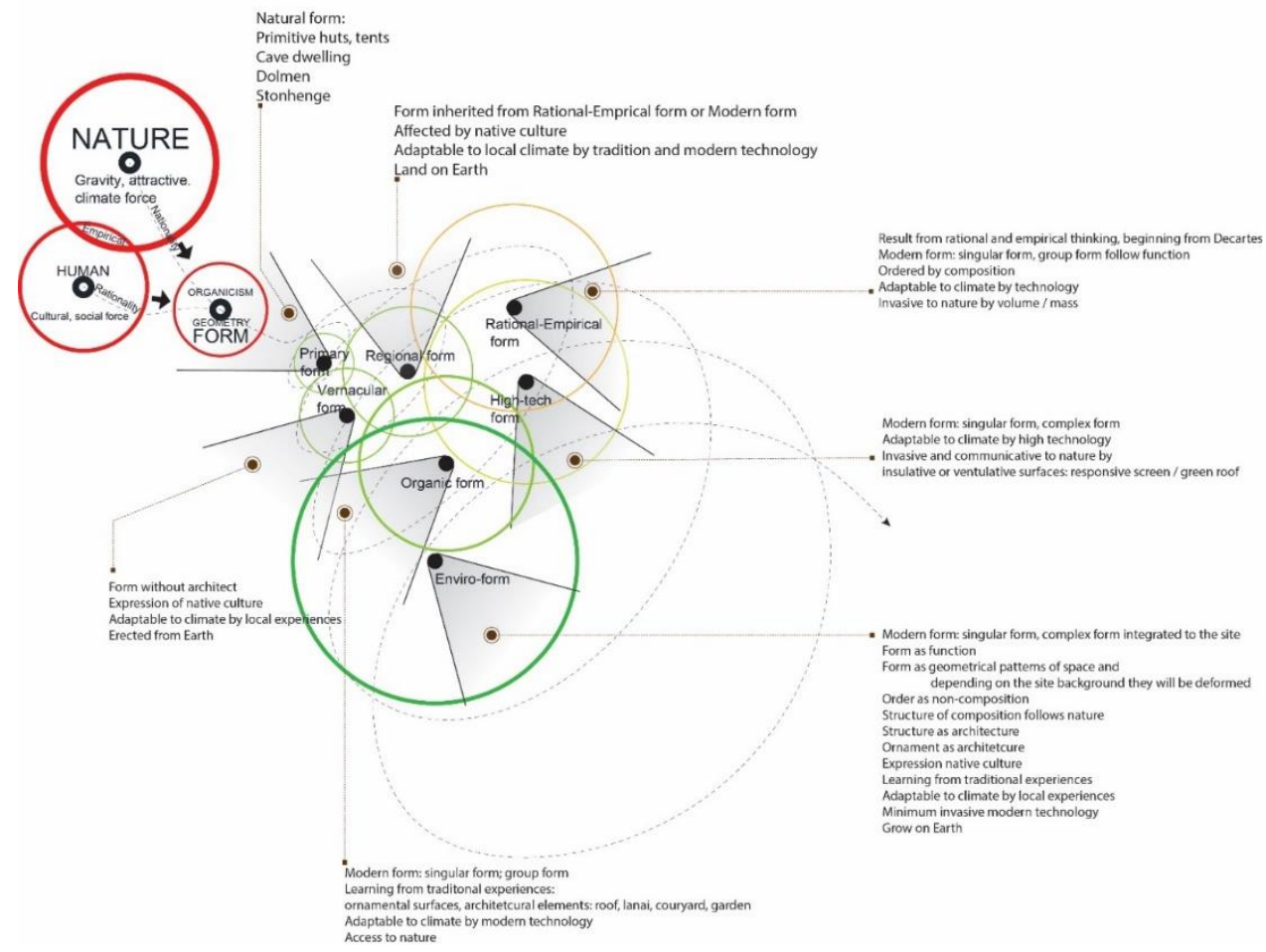

Fig. 1. Transformations of form.

\subsection{The enviro-organic form integrating to the built environment}

Following the organic flow, we can see that various concepts at each era of architecture contain different forms due to changes in human perception. These forms influence perception, and in turn give birth to new form. They result from nature's conditions and human demands with regard to function and meaning under aesthetic psychology. The process of looking for the unity of form, function and meaning is still going on, and never ending. It is important to now return to a study of nature's growth and form to understand key concepts to allow the concept of organicism to evolve further. In common with Darwinian evolution and the transformational morphology of D'Arcy Thompson, an enviroorganic form grounded on prior forms is proposed in response to current social and environmental needs. This form inherits from strong points of those previous organic forms and is influenced from its place as a part of that place that it grows from the earth. In that way, the form as the whole organic accumulates demands of function and meaning including the natural and rational, to become "genius loci" in its built environment.

\subsection{Primitive form}

Prior forms of organicism can be summarized in six types. In prehistory, the demands given by inhabitation or cultural and social forces are very minor. Organic forms include cave dwellings, primitive huts, tents, and selected monumental structures such as Dolmen and Stonehenge. The imitation of nature is totally dependent on nature and thus those forms called primitive form are maintained in geometrical patterns such as cone, hemisphere, cube, square, circle, etc. 


\subsection{Vernacular form}

Vernacular form is the next phase of transformation of primitive form with higher needs because of an increased social and cultural force. It is the form without the architect, that directly and simply expresses native culture, and that adapts to local climate. It is erected from the Earth by indigenous experiences. Usually, added elements of vernacular form adapt to the new demands to include high-pitched roofs, eaves, yards, gardens, and porches.

\subsection{Rational-empirical form}

With the development of the modern science of nature based on methodological skepticism, rational- empirical form results from human rational and empirical thinking begun by Descartes. It is pure geometrical form, or modern forms such as box and sphere, that constitute singular form or grouped form in architecture adaptable to nature by technology. Rational-empirical form appears as invasive to nature by its volume or mass.

\subsection{High-tech form}

Accordingly, high-tech form is created by singular and complex form that is deformed, such as bending or twisting, in order to satisfy human demands in the digital age. This form is adaptable to climate by use of high technology. It characterizes features invasive and communicative to nature by surfaces such as green screen and roof.

Organic form implies form of pure Organic Architecture. Its form language is the same as modern form but it is associated with traditional experiences of handcraft for the purpose of representation of space and time and integration to site, such as ornaments on surfaces, supplement of architectural elements: high-pitched roof, lanai, yard, eaves, and garden. This form adapts to climate by modern technology and yet retains more direct access to nature. In an attempt to find equilibrium between nature and human forces, regional form combines vernacular, rational-empirical form, high tech, and organic form. It is impacted by native culture. And it lands on earth and responds to local climate by tradition and modern technology.

\subsection{Enviro-organic form}

Enviro-organic form results from the advantages of previous forms and integrates to its site with modern form including singular and complex form. The organic whole is organized following natural principles and its form is influenced by its natural environment. Ornament is no longer used as surface decoration, but integrated into form. This enviro-form responds to traditional experiences adaptable to nature and human culture such to minimize the invasion to the environment by modern technology. Its process is taken to be a "growing on earth". The expression of enviro-organic form consists of form and structure. Because of human agency, enviro-organic architecture cannot literally grow as a natural form. However, the process of producing such form must be considered, because the final form is reflective of its process of coming into being. There is first an indefinite arrangement of spatial units grounded on site, which are in turn deformed by the forces present that include the cultural, material, environmental, structural, and psychological.

\section{Discussion}

Organicism, the process of growth in general, from mimesis to imitation of nature, focuses 
on how to make buildings similar to nature. Humans learn from nature and replicate and symbolize it. These strategies are not limited to Organic Architecture but are also seen in other modern architectural movements [8].

The ideas of the whole of geometric interweavement, tradition, ornament, and force based on natural principles as developed by Sullivan, Wright, and Gaudi have been continued and expressed by architects up to the present. European architects are influenced by these concepts to varied extents, and their organic forms are made by a following traditional design and local culture, such as Imre Makovecz's buildings: Sport Hall, Visegrad, 1985, Expo'92 Pavilion in Serville, Hungary, and Onion House, Mako, 1995. Other architects extend these ideas by considering landform and social context in their designs.

Some buildings are placed completely or partially below ground, such as EFA Radio Satellite Station, designed by Gustav Peichl, and Nine Houses, Dietikon, Switzerland by Peter Vetsch. The Eden Project, Cornwall, UK is an example of cells forming a whole interrelated to its site. In Asia, Truss Wall House and Soft and Hairy House designed by EisakuUshida and Kathryn Findlay are examples of primitive singularity in which nature is exploited by voids and complicated curved shapes. The development of organicism directed by consideration of physical forces is seen in architect Frei Otto's work. His Munich Olympic Park designed in 1972, is one of his attempts to align architectural/structural form with natural form [9- 11].

Modern architecture attempts, through a process of abstraction, to capture the great variety of natural forms. Certain modern architects, including Le Corbusier, Walter Gropius, and Peter Eisenman, have developed different interpretations of how to make organic architecture. However, their works do not directly show the relationship of natural forces and their impact to the architectural form.

Creativity is theoretically limitless but human creation itself is limited. A rationalist movement in architecture attempted to divorce buildings from nature. However, a number of architects that previously held rationalist tendencies are starting to return to an appreciation of nature as inspiration for their designs [12]. For example, Frank Gehry finds his relations with Bruce Goff late in his career:

"I knew of Goff in my architectural beginning as a shadowy mystical figure in Oklahoma who made bizarre buildings ... Goff talked about the intuitive in a way that I find familiar. His discussion about connecting to the other arts, to music and painting, are more areas and coincidence. He expressed ides to their limits. He talks about awkwardness, irresolution, and the unfinished. These are all issues and ideas that move me also." (Alan Hess, "Organic Architecture Today," in Organic Architecture: The Other Modernism, pho. Alan Weintraub (Salt lake City: Gibbs Smith, 2006), 186).

From the all observations above, humans still are looking for a new way for making form and organicism is tending to be translated to a new position [13, 14]. Some organic forms are inspired by the natural setting to blend their forms into rocks, fields, hills, and lakes. Other have used those images metaphorically, echoing the natural landscape, of caves, meadows, and forest. Others are inspired by abstract principles of natural structure, mimicking the way a tree that integrates strong trunks, hidden widespread roots, and delicate leaves into a single unity. Some others are inspired by the lateral shapes of flowers, birds, bones, and crystals. Henry Whiting Residence, designed by Bart Prince and Desert House in California, designed by Kendrick Bangs Kellogg, Science City, International Competition 2016, First Prize, Second Prize, and Third Prize are the notable examples of those characters. This research implies that organicism does not stop at imitation of outside phenomena, but further seeks to learn their essence from their conformations and interrelations. Forms interact mutually between nature and the built environment.

\section{Conclusion}


Organicism is the result of human interaction to nature. From mimesis to imitation, organism flows continuously in human life and is always applied in architecture and other human productions. Organicism not only includes aspects of the natural, but also rational aspects, such as useful form, function, structure, and symbol. It unfolds the integration of humans to nature, with architecture being one of the results. Enviro-organic form is not merely organic or rational but amalgamative. The degree to which the organic is enmeshed in the production of form depends on human need and cognition experienced during human evolution. The enviro-organic approach is proposed as a means to bring humans closer to a richer and fuller organic horizon. This approach is argued to be a promising direction for future architecture. It shows human potential in connecting earth to sky in making his dwelling in the world.

\section{References}

1. C. van Eck, Organism in Nineteenth-century Architecture: An Inquiry into Its Theoretical and Philosophical Backgrounds (Architectura\& Natura, Amsterdam, 1994)

2. D. Gans, Z. Kuz, The Organic Approach to Architecture (Wiley-Academy, John Wiley $\&$ Sons Ltd, Great Britain, 2003)

3. D. Pearson, New Organic Architecture: The Breaking Wave (Gaia Books Limited, London, 2001)

4. D'Arcy Wentworth Thompson, On Growth and Form (The University Press, Cambridge, 2014)

5. E.A. Scheurer, The Continuous Present of Organic Architecture (The Contemporary Arts Center, Cincinnati, 1991)

6. S. Bonnemaison, P. Beesley, On Growth and form: Organic Architecture and Beyond (TUNS Press, Halifax, 2008)

7. V. Olgyay, Design with Climate: Bioclimatic Approach to Architectural Regionalism (Princeton University Press, Princeton, 1962)

8. A. Weintraub, A. Hess, Organic Architecture: The Other Modernism (Gibbs Smith, Layton, Utah, 2006)

9. J. Senosiain, Bio-Architecture (Architectural Press, Oxford, 2003)

10. J. Wines, Green Architecture (Taschen, Italy, 2000)

11. B. Zevi, Towards an Organic Architecture (Faber \& Faber, London, 1950)

12. J. Balu, S.Y. Kulkarni, International Journal of Engineering Research and Technology 3(5), 1523-1527 (2014)

13. L. Thomas, Journal of Architectural Education, 45-54 (2003)

14. M. Zbašnik-Senegaènik, M. Kitek Kuzman, Scientific Papers 2(22), 291-299 (2014) 